\title{
Cautionary notes on teaching water safety skills
}

\author{
Peter Barss
}

Asher et al, authors of the paper in this issue on teaching water safety skills, are to be commended for attempting to provide an answer to a difficult and controversial problem - whether an educational program can prevent swimming drownings among high risk toddlers (see p 228). However, their work demands cautious scrutiny in view of the fact that it will be read by organizations which have a vested interest in the results because they derive revenue from such programs. The results may be used to support educational activities for toddlers at the expense of overlooking automatic passive preventive measures that have proven to be more effective.

When one considers the small sample size, lack of a control group, failure to validate assessments by an independent observer in at least a subsample of the group, and other methodological problems discussed below, the potential benefits of such programs on outcome still remain to be proven. Conversely, the demonstrated and potential risks of similar swimming programs for small children has led the American Academy of Pediatrics to take a position against them. In summary, the many limitations of this report must be carefully considered until a more definitive study or studies have been completed.

Interventions assessed by repeated measures are often confounded by factors other than the intervention, including rapid development with increasing age in toddlers and exposures other than the treatment or program. Furthermore the lack of a control group makes it impossible to fully and properly assess the impact of most interventions. The relative influence of other sources of instruction or experience in the water on the measured variables, during and after the study, was also not assessed. In this instance there was a large difference in swimming ability between the two groups when they started the program (with a gap of four weeks). The average swimming ability of the group with higher socioeconomic status was much greater than the other group. This suggests either effects from something other than the program or a large difference between the two study groups arising from non-random allocation.

Because the study assessed mainly children of mid and upper income level the results cannot be widely generalised. Future studies should include low income populations. The inaccessibility or impracticality of long courses of this nature for an average family in the general population, and the lack of generalizability of the study in view of the relatively high socioeconomic status of many families, must be borne in mind.

A central concern is that the study did not and ethically could not assess the ability of a child to recover and independently exit from a pool after a fall in an unsupervised situation, nor the potential risk of giving swimming instruction to small children in less than ideal situations. As well, it failed to assess the potential for increased exposure to aquatic hazards and the associated risks of drowning and/or near drowning, during and after the program. Because follow up was brief and the sample size was small, it cannot be established that the program may not have increased the risk of drowning. This is conceivable because the program may generate overconfidence on the part of children and/or their parents. As the authors themselves state, there are about six deaths per 100000 population per year while their sample size was only about 100 , with a follow up of 12 weeks.

In conclusion, the results of this study should be considered as a small but highly interesting pilot, and not as a definitive answer to the risks and benefits of including small children in swimming programs. As is often the case, it raises more questions than it answers. Organizations that include drowning prevention among children as one of their main goals should be careful not to abandon their efforts to support and initiate legislative and other strategies to promote preventive measures that have been scientifically proven to be effective.

Relatively few toddlers drown during swimming or during other aquatic activities. ${ }^{1-3}$ Most toddler pool drownings in Canada occur when children are walking or playing alone near an unprotected swimming pool and fall in. Automatic protection is needed to provide a safe user friendly environment in residential areas. Municipalities should ensure that home swimming pools are never installed or filled until a good fence has been erected and equipped with a sturdy self closing, self latching gate. Annual pool licensing fees could be used to recover the costs of pool surveillance and thus ensure that pool owners, and not their neighbors, pay the costs of drowning prevention.

In fact, the main justification for swimming instruction for children is not simply a question of safety. Mastery of swimming skills offers pleasure from participation in aquatic activities. The question as to whether such instruction should begin with toddlers remains open and should not be allowed to distract from 
implementation of other effective measures for this vulnerable group.

1 Canadian Red Cross Society. Drownings among 1 to 4 years old children in Canada: a high risk group for water-related fatalities. Ottawa: Canadian Red Cross Society, 1994. (Special research report: 1-32.)

2 Canadian Red Cross Society. National drowning report. Analysis of water-related fatalities in Canada for 1992. Ottawa: Canadian Red Cross Society, 1994. (Annual surveillance report: $1-108$.)

3 Canadian Red Cross Society. Swimming and water safety. Ottawa: Mosby Lifeline, 1995: 1-308.

\section{Photo quiz contest}

Send your answers to the following questions to the editor. The first set of correct replies will receive a $C D$.

- What role does this man have in injury causation?

- Give three examples.

- For each, recommend a preventive measure.

- Where does his name originate?

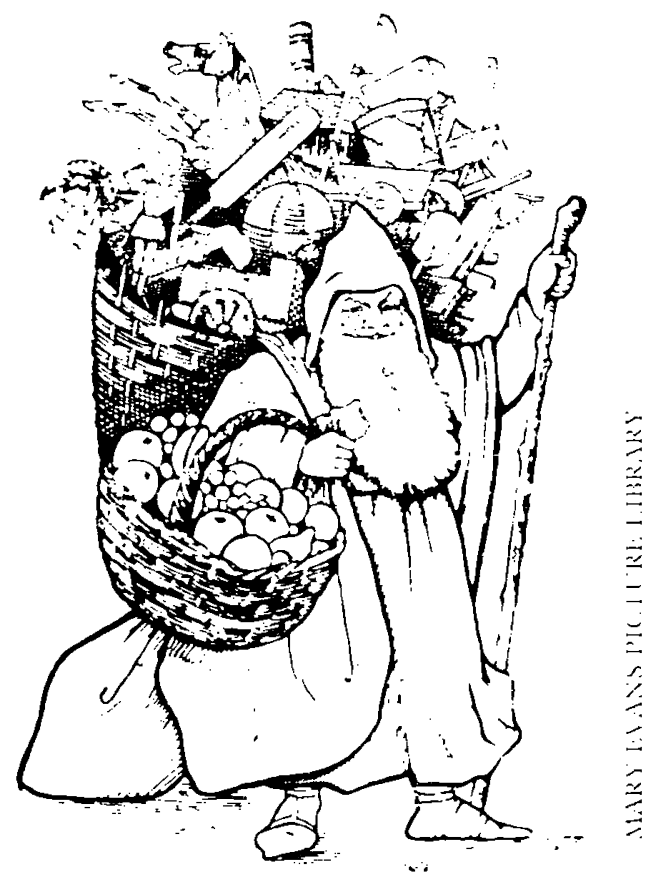

Advertising slogans

A propos of nothing whatsoever related to injuries, two entries from a contest for clever slogans. First, my favourite (for a camping store), 'Now is the discount of our winter tents'. S Second, for a firm of morticians, 'Trust us, we'll be the last to let you down'.

\section{Other useful (?) slogans}

'Ideas don't work unless you do'.

'Learn to recognize the inconsequential - then ignore it'.

\section{Drunk drivers}

Despite a drop in the death toll on Quebec roads, the Minister of Transport is calling for a crackdown on drunk drivers that would include an immediate license suspension. 